$\begin{array}{cccc}\text { State } & T_{e} & m & \text { Initial potential } \\ B & 20,320 & 2 \cdot 325 & 40,610 \\ C & 29,393 & 3 \cdot 325 & 39,313 \\ D & 33,440 & 4 \cdot 325 & 39,300\end{array}$

Thus the ionization potential $\left(\mathrm{Na}_{2}\right) \sim 39,300 \mathrm{~cm} \cdot{ }^{-1}$. Since the ionization potential $(\mathrm{Na})=41,450 \mathrm{~cm} .^{-1}$, this implies that $D\left(\mathrm{Na}_{2}{ }^{+}\right)$is greater than $D\left(\mathrm{Na}_{2}\right)$ by about $2,150 \mathrm{~cm}^{-1}$ or 35 per cent. At first sight, this is a very surprising conclusion, but, as Prof. Coulson has pointed out to us, theoretical calculations ${ }^{9}$ indicate that $\mathrm{Li}_{2}{ }^{+}$is more stable than $\mathrm{Li}_{2}$ by about $1,200 \mathrm{~cm}^{-1}$.

R. F. BARROW

N. Travis

C. V. WRIGHT

Physical Chemistry Laboratory, University of Oxford.

1 James, J. Chem. Phys., 2, 794 (1934).

${ }^{2}$ Arai and Sakamoto, J. Chem. Phys, 28, 32 (1958).

${ }^{3}$ Dicke, J. Mol. Spectroscopy, 2, 494 (1958).

4 Herzberg and Howe, Canad. J. Phys., 37, 636 (1959).

'Herzberg, "Molecular Spectra and Molecular Structure, I. Spectra of Diatomic Molecules" (New York, 1950).

- "Données Spectroscopiques concernant les Molécules diatomiques", edit, by Rosen (Paris, 1951).

${ }^{7}$ Sinha, Ind. J. Phys., 22, 401 (1948).

${ }^{8}$ Fvans, Jacobson, Munson and Wagman, J. Res. Nat. Bur. Stand., 55, 83 (1955).

'James, J. Chem. Phys., 3, 9 (1935).

\section{Infra-Red Frequency Shifts}

THE effect of liquefaction and solution in different solvents on infra-red group frequencies has previously been considerod in terms of changes in dielectric constant and postulated local association effects (for example, Caldow and Thompson ${ }^{1}$, and Bellamy and Williams ${ }^{2}$. A more fundamental approach would seem to be to relate the shifts to the actual solutesolution interaction energy.

At infinite dilution the solute-solution interaction energy is given very approximately by :

$$
E_{1 S}=E_{12}=\frac{1}{2}\left[L_{1}+\left(\frac{V_{1}}{V_{2}}\right)^{n} L_{2}-\Delta \bar{E}_{1}\right]
$$

where $L_{1}, L_{2}$ and $V_{1}, V_{2}$ are the internal latent heats and molal volumes of solute and solvent respectively, and $\Delta \bar{E}_{1}$ is the partial molal heat of mixing at infinite dilution. The value of $n$ varies with the solvent, but in the absence of data will be taken to be $\frac{2}{3}$ (this amounts to the assumption that the energy required to form a hole is proportional to its surface area).

Fig. 1 is a plot of $E_{1 S}$ against the fractional frequency shift, $\frac{\Delta \nu}{\nu}$, of the carbonyl group in acetone in solution in various solvents as reported by Bellamy and Williams ${ }^{3}$. The values of $\Delta \bar{E}_{1}$ were obtained from the International Critical Tables ${ }^{4}$ except those for acetonitrile and nitromethane which were calculated from the data of Brown, and Foek at $45^{\circ} \mathrm{C}$. assuming no change with temperature (this may be a poor approximation). Evidently to a fair approximation :

$$
\frac{\Delta v}{\nu}=\frac{E_{1} S}{K}
$$

where $K$ is a constant equal to $5.4 \times 10^{5} \mathrm{cal} . / \mathrm{mole}$ for acetone. Because of lack of data it has not been possible to demonstrate the validity of equation 2 for solutes other than acetone; but if the relation is generally true the frequency shifts for different groups in the same molecule should be rectilinearly related.

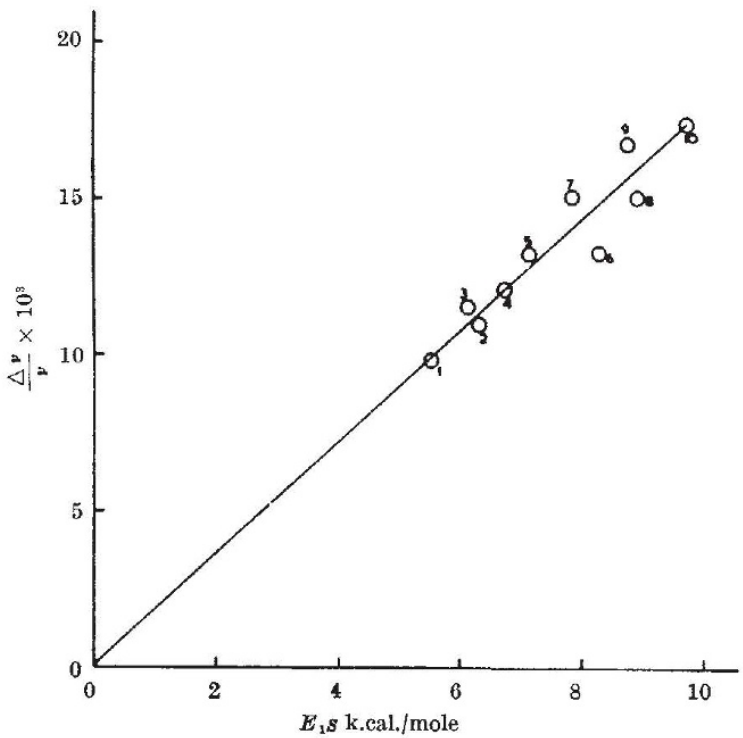

Fig. 1. Variation of frequency shift of acetone carbonyl group in different solvents with solute-solution interaction-energy The solvents are: 1 , ether; 2 , carbon tetrachloride; 3 , carbon disulphide; 4, benzene; 5 , acetone; 6 , acetonitrile ; 7 , chloroform ; 8 , nitromethane; 9 , ethanol ; 10 , methanol

Such a relationship has been shown to exist for a number of molecules (for example, Bellamy, ref. 6).

It is evident from consideration of the frequency shifts on liquefaction that the value of $K$ is different even for the same group in different molecules; this is presumably connected with the way in which the interaction energy is distributed among the degrees of freedom as well as with differences between the force constants of the bonds.

If equation 2 is found to be generally valid, the much-discussed question of what proportion of the frequency shift is attributable to non-specific interactions can be considered in terms of the extent to which pure dispersion energy contributes to the latent heats and heat of mixing.

The Distillers Co., Ltd.,

R. S. NORRISH

Research and Development Department,

Great Burgh, Epsom, Surrey.

${ }^{1}$ Caldow, G. L., and Thompson, H. W., Proc. Roy. Soc., A, 254, 1 (1960).

${ }^{2}$ Bellamy, L. J., and Williams, R. L., Proc. Roy. Soc., A, 255, 22 (1960).

${ }^{3}$ Bellamy, I. J., and Williams, R. L., Trans. Farad. Soc., 55, 14 (1959).

" "International Critical Tables" (McGraw-Hill, New York, 1929).

${ }^{s}$ Brown, I., and Fock, W., Austral. J. Chem., 10, 417 (1957).

"Bellamy, I. J., "The Infra-red Spectra of Complex Molecules", second ed., 404 (Methuen, London, 1958).

\section{Two Highly Selective Solvents for Gas- Liquid Chromatography Analysis of $\mathrm{C}_{2}-\mathrm{C}_{6}$ Hydrocarbons}

In the course of a systematic investigation of polar stationary liquids for gas-liquid chromatography at a column temperature of $30^{\circ} \mathrm{C}$., it was found that dimethyl sulphoxide $\left(\mathrm{CH}_{3} \mathrm{SOCH}_{3}\right.$, b.p. $189^{\circ}$ C. $)$ and sulpholane (tetramethylene sulphono, $\left(\mathrm{CH}_{2}\right)_{4} \mathrm{SO}_{2}$, b.p. $284^{\circ}$ C.) are very suitable for the analysis of complex $\mathrm{C}_{2}-\mathrm{C}_{6}$ hydrocarbon mixtures. Under the conditions used (sec below), columns charged with 